\title{
DE ACCOUNTANTSCONTROLE VAN EEN \\ LEVENSVERZEKERINGSMAATSCHAPPIJ EN DE VERKLARING BIJ DE JAARREKENING ERVAN
}

\author{
door J. C. Haak
}

\section{Inleidende opmerkingen}

In de Nederlandse accountantsvakliteratuur is het over het algemeen gebruikelijk een probleem in zijn algemeenheid te onderkennen en daarna te komen tot een fundamentele abstrakte behandeling. Bij voorkeur hanteert iedere schrijver een serie definities naar eigen ontwerp en ontwijk tillustratie met reële voorbeelden. De wetenschappelijke waarde van deze methode is boven alle twijfel verheven, terwijl tevens vaststaat, dat de gebruiksnuttigheid niet altijd optimaal is.

In dit artikel wordt daarentegen getracht om, uitgaande van een geconstateerde situatie, enige kritische opmerkingen te maken, die vanuit de abstrakte benadering (als konsekwentie van een logisch gedachtenpatroon) niet of niet voldoende naar voren zijn gebracht.

Uitgegaan wordt van een globale bekendheid met het levensverzekeringbedrijf (voortaan te noemen l.v.b.), dat gekenmerkt wordt door het collectief of individueel afsluiten van contracten, welke voor hem verplichtingen met zich meebrengen, afhankelijk van het onzekere voorval van het moment, waarop een bepaalde persoon overlijdt en/of het tijdstip, waarop deze nog in leven is. Deze contracten hebben veelal naar hun aard een lange looptijd. Bedrijfseigen is voorts - dit wordt met nadruk vermeld - het beleggen van de bedragen, welke als premies en koopsommen door de polishouders zijn gestort.

De Verzekeringskamer, een bij de Wet $^{1}$ ) ingesteld lichaam, houdt ten behoeve van de polishouders toezicht op het l.v.b. en zijn rapportering. Voorts is er de actuaris, die op grond van eigen specifieke deskundigheid de verantwoordelijkheid neemt voor een bijzondere passiefpost op de balans. Is nu een eventuele goedkeurende (accountants)verklaring te beschouwen als een aanvulling op reeds bestaande zekerheid bij het maatschappelijk verkeer? En sluiten de accountantswerkzaamheden aan op reeds geformuleerde verantwoordingen of dient de ,,deugdelijke grondslag" zelfstandig gelegd te worden? Duidelijk moet m.i. zijn, dat aan de zekerheid, welke van de goedkeurende verklaring uitgaat, een hogere waarde moet worden toegekend dan een additionele ten opzichte van de verklaring van de actuaris (die als fragmentarisch kan worden gezien) en de zekerheid welke het toezicht van de Verzekeringskamer biedt. De reden hiervan is, dat de accountant als controledeskundige bij uitstek de onderneming in haar totaliteit in zijn onderzoek betrekt en zijn verklaring afgeeft bij de gehele jaarrekening. De ,,gecon-

\footnotetext{
1) De citeertitel van deze Wet luidt: Wet op het Levensverzekeringbedrijf (Stb. 1922, 716). Het jaaroverzicht 1973-1974, zowel als het ,verslag van de werkzaamheden" 1973-1974 van het NIvRA voegen een extra $s$ toe aan deze titel, wellicht om aan te sluiten bij het spraakgebruik. Ik vraag mij af, of deze onnauwkeurigheid een symptoom is van het nog nader te behandelen "deskundigheidsmanco" of van gebrek aan interesse voor deze bedrijfstak.
} 
solideerde functie" blijft dus voor de openbare accountant zoals die bij iedere andere huishouding is.

\section{De betekenis van de interne controle}

Bij het NIvRA- (en voorheen NIVA-)onderwijs in de Leer van de Administratieve Organisatie, zowel als in de Controleleer komt het l.v.b. als één van de laatste typologische toepassingen aan de orde. Dit is duidelijk het gevolg van een controlebegrip, dat gekoppeld is aan het kringloopidee (A. Mey). Dat de interne organisatie de accountant een reële mogelijkheid biedt om zijn deugdelijke grondslag te verkrijgen, kwam pas laat, in moeizaam verlopende discussies, van de grond. De klassiek opgeleide accountant moet dus wel met enige schroom over de drempel getreden zijn, het l.v.b. in, waar de goederen, evenals de vorderingen en schulden niet bewegen en ook het geld niet beweegt. (N.B.: Het is een solide maatschappij!)

Reeds een tiental jaren voor de Tweede Wereldoorlog hebben diverse l.v.mijen goedkeurende verklaringen van een accountant bij hun jaarrekening. Men zou verwachten, dat de ervaring hier opgedaan met het werken met c.q. steunen op c.q. gebruik maken van de interne controle een bijdrage van belang zou leveren in de discussie, die in de vijftiger jaren ontstaat als gevolg van moderne (Amerikaanse) controletechnieken. Merkwaardig is het te moeten constateren, dat een inbreng van deze zijde of argumenten uit deze bestaande controlerealiteit slechts sporadisch te vinden zijn. Het academisch slagveld is en blijft: de handelsonderneming! De uitspraak van Prof. Drs. R. Burgert in 1960: ,Persoonlijk acht ik een synthese tussen de twee standpunten via de methode van de mathematische steekproef zeer wel mogelijk" zou men kunnen beschouwen als het ei van Columbus, ware het niet, dat jaren later blijkt, dat deze standpunten nog even controversiëel zijn. Inmiddels schijnt deze discussie in haar laatste stadium te zijn. Een aantal artikelen in het $\mathrm{MAB}$ van dit jaar, alsmede de analyse van $\mathrm{H}$. J. de Heer geven afdoend geargumenteerd de plaats aan, welke de interne controle inneemt in het onderzoek van de controlerend accountant. Persoonlijk acht ik de uitspraak van J. P. van Rossem zonder meer een vondst: ,De interne controle is object van accountantscontrole in het kader van de eigen actie, die nodig is om tot een eigen oordeel te komen". Leest men voor ,eigen oordeel” „deugdelijke grondslag" (wat in feite ook bedoeld wordt) dan ziet men op welk een kostelijke wijze separaat geachte begrippen ,eigen actie" versus ,,object van de accountantscontrole is de beoordeling van opzet en werking van de interne controle" geïntegreerd worden.

\section{Actuaris en Accountant: Het Deskundigheidsmanco}

De mathematische problematiek van het l.v.b. behoort tot het specifieke werkterrein van de actuaris. Veelal zetelt deze deskundige op de Wiskundige Afdeling. In zekere zin is hij een „Jongen van Johan de Witt”, auteur van het boekje "Waerdye van lijfrente naar proportie van los-renten" (1671). Hij wordt beschouwd als een intern functionaris, die een eigen verantwoordelijk- 
heid accepteert middels de ondertekening van de staten L15 en L16 (Actuariëel Verslag en Premiereserve). Het lidmaatschap van het Actuariëel Genootschap impliceert het onderworpen zijn aan een tuchtrecht, dat waakt over het aanzien van de stand van de actuarissen.

De noodzaak van de verwijzing in de goedkeurende verklaring naar (de berekening van) de actuaris wordt steeds gemotiveerd door te stellen, dat deze een deskundigheid bezit, welke de accountant als zodanig niet eigen is.

Deze deskundigheid vindt zijn hoogtepunt in het berekenen van de Premiereserve ${ }^{2}$ ). De faktoren, die hierbij een rol spelen - uitgaande van het polisbestand - blijken bij analyse de volgende te zijn:

a. sterfteverwachtingen,

b. opbrengstenverwach tingen ( $\approx$ renteverwachtingen),

$c$. kostenverwachtingen (de zogenaamde doorlopende kosten), terwijl nog resteert:

d. de methode van berekening (netto, bruto, Zillmer, etc.),

$e$. de berekening zelf.

De vraag is nu: Waar zit het deskundigheidsmanco van de accountant? Als bedrijfseconomisch gevormd expert moet hij in staat zijn zich over de punten b., c. en d. een gefundeerd oordeel te vormen. Het punt a. ligt vast in officiële tabellen, terwijl het punt e. hem zal herinneren aan zijn exercities aan het prille begin van zijn opleiding. Van Modijefsky vernemen we, dat het „op zichzelf tamelijk eenvoudige formules" zijn, zodat de accountant zich hierin met vrucht kan verdiepen. Maar er is meer. Te noemen vallen de begroting en de analyse van de verschillen zoals die naar voren komen op de organisch ingedeelde resultaten-rekening. Deze analyse dient plaats te vinden in goede samenwerking tussen accountant en actuaris. Alsdan zal de accountant zeker in staat zijn zich een oordeel te vormen over de aanvaardbaarheid van de Premiereserve.

De eerlijkheid gebiedt me nu ook eens de vraag te stellen die in de vakliteratuur ontbreekt, n.l.: Waar zit het deskundigheidsmanco van de actuaris? Zonder een volledigheidspretentie te koesteren, wil ik naar voren brengen, dat zijn sterk wiskundig georiënteerde opleiding geen aandacht schenkt aan bedrijfseconomie en controleleer.

Hoe men zich wiskundig een oordeel vormt over de hierboven omschreven punten b. en c. is me in het geheel niet duidelijk, evenmin als hoe men de wiskundige kennis aanwendt om een organisatie op de Wiskundige Afdeling te creëren, die een goede berekening van de Premiereserve waarborgt. (Voorts valt te noemen: de automatisering met haar eisen van interne con-

2) Premiereserve is de wettelijke term voor het begrip, dat in de wandel Wiskundige Reserve genoemd wordt. Beide uitdrukkingen hebben het onjuiste woord "Reserve" gemeen. Het woord "Premie" duidt op een onjuist begrip, omdat het in wezen niet gaat om in het verleden ontvangen (opgespaarde) premies, maar om de toekomstige uitkeringen (minus toekomstige premies). „Wiskundig" betekent ,wiskundig bepaald" en zou bevredigend kunnen worden geacht, ware het niet, dat achter het wiskundige cijferwerk een bedrijfseconomische grondslagbepaling schuil gaat. (De grondslag is bedrijfseconomie, het hulpmiddel wiskunde, de bouwstenen zijn de afgesloten contracten.) De contracten veroorzaken de schuldpositie. Persoonlijk acht ik "Verplichtingen uit hoofde van Levensverzekering” of kortweg „Verplichtingen Levensverzekering” een keurige, duidelijke en eerlijke omschrijving. 
trole. In principe valt dit punt onder de organisatie van de Wiskundige Afdeling, hoewel men zich de integratie met de hoofdadministratie niet lange tijd meer als zuiver denkbeeldig moet voorstellen.) Uiteraard zal de actuaris zich in de praktijk op genoemde vakgebieden ontwikkelen en op een gegeven ogenblik meer dan een contactdeskundigheid gaan bezitten. Niettemin acht ik het van het grootste belang dat men zich realiseert, dat actuariële kennis op zich geen deugdelijke basis kan vormen voor een verklaring die in het maatschappelijk verkeer vertrouwen moet wekken.

\section{De verwijzing}

Onder diverse bewoordingen komt nagenoeg steeds in de goedkeurende verklaring de verwijzing voor naar de actuaris, de berekening van de actuaris of de verklaring van de actuaris. Wanneer het indirect de bedoeling is hierin een voorbehoud te zien (niet direct, immers dan volgt uit de redactie van artikel 13 GBR ,niet wezenlijk afbreuk doen", dat dit niet mogelijk is; indirect betekent hier: de actuaris begrijpt beter dan ik hoe deze post gewaardeerd moet worden, het gaat om de grondslagen en de berekening) dan ontstaat er een onbevredigende situatie ten gevolge van het feit, dat de accountant zich, m.i. ten onrechte, distantiëert van een belangrijke balanspost door een discipline voor te stellen, die (let wel: in de verklaring) in feite overbodig is. Immers met betrekking tot de bedrijfseconomische aspecten dient hij zich in ieder geval een oordeel te vormen en de berekening kan hij controleren. ${ }^{3}$ )

Op dit moment wil ik de vraag lanceren die me al tijden bezighoudt, n.l.: Is het verwijzen naar de actuaris te beschouwen als een schroomresidu bij de accountant, stammend uit de tijd dat hij allerminst de indruk had een omspannende totaalcontrole te kunnen uitvoeren?

Het bijzonder lezenswaardige artikel van Drs. I. Kleerekoper „De accountant in zijn verhouding tot andere beroepen" levert mij een uitstekend uitgangspunt op voor de vergelijking van de verwijzing naar de actuaris en naar andere vrije beroepsuitoefenaars. Immers, in het artikel treft men een inventarisatie aan van diverse raakvlakken met andere disciplines. Merkwaardig, uiterst merkwaardig m.i., werd de navolgende inkonsekwentie verwerkt. De makelaar-taxateur, die de voorraad diamant van een diamantslijperij als echt waarmerkt en in overeenstemming met de beweerde kwaliteit, valt niet de eer te beurt een verwijzing ex artikel 16 GBR in de goedkeurende verklaring aan te treffen. Volgens Kleerekoper is in bovenomschreven geval de vermelding niet noodzakelijk voor de motivering van de strekking van de verklaring (en dient dus achterwege te blijven) nu het de accountant bij de inschakeling van de deskundige "slechts" gaat om de bevestiging van grootheden, die hem uit verbanden binnen de administratie bekend waren. Of deze argumentatie juist is, mede gelet op de mededeling, dat de organisatie rondom de voorraad-

3) Prof. A. B. Frielink (in een noot op de verwijzing van art. 16 GBR, zie lit.lijst) doet het voorkomen, alsof de accountant computerprogramma's nodig heeft voor deze controle. Van wezenlijke betekenis acht $i k$ evenwel de computer in dit verband niet. Dit is een punt van uitvoering en niet zozeer van realiseerbaarheid. Wel van belang is in hoeverre de actuaris nog geneigd is zijn praktisch onontbeerlijke medewerking te verlenen. 
bewaring en -bewaking zelden optimaal is, laat ik voor rekening van de schrijver. Van belang is voor mij, dat voor de accountant bij de l.v.mij evenzeer geldt, dat de verbanden van begroting en analyse van de resultaten hem al een duidelijk beeld geven van de omvang van de Premiereserve op de balans.

Tenslotte valt er nog te vermelden: een inkonsekwentie in de beroepsuitoefening. Voorzover mij bekend, wordt door niemand bestreden, dat de externe accountant in zijn verklaring niet kan verwijzen naar de interne accountant. Algemeen wordt de onafhankelijkheid niet volkomen geacht, uiteraard zonder een oordeel te vellen over de persoonlijke gesteldheid van de desbetreffende functionaris. Evenwel dienen dezelfde eisen van onafhankelijkheid gesteld te worden aan andere ,,deskundigen", daar het immers gaat om de waarde van een verklaring in de ogen van het zogenaamde maatschappelijk verkeer. Het verbaast me, dat de bescheidenheid van de als intern accountant fungerende Registeraccountants hen tot nu toe heeft weerhouden dit punt eens duidelijk en geargumenteerd onder de aandacht te brengen. Prof. A. B. Frielink spreekt in dit verband van een onvolkomenheid. (De GBR verklaard, blz. 58.) Voor accountants in hun terminologie een woord met een duidelijke betekenis. Onvolkomen is een synoniem van: onjuist, fout.

\section{De goedkeurende verklaring bij de jaarrekening}

De weergave van grootte en samenstelling van het vermogen, alsmede grootte en samenstelling van het resultaat, dient in het kader van de Wet op de Jaarrekening getrouw en stelselmatig te zijn. Aan deze eis dient ook de jaarrekening van een l.v.mij te voldoen. Artikel 36 van de zojuist genoemde wet geeft evenwel aan de Verzekeringskamer bijzonder vergaande bevoegdheden m.b.t. de grondslagen van waardering en resultaatsbepaling: Normen, die in het maatschappelijk verkeer als aanvaardbaar worden beschouwd (toetsing door de Ondernemingskamer), dienen door de Verzekeringskamer nog beoordeeld te worden met het oog op de mate van veiligheid, welke zij noodzakelijk acht ter verkrijging van een waarborg voor de belangen van polishouders. Het potentiëel wantrouwen van de Verzekeringskamer van maatschappelijk aanvaardbare normen dient de accountant, die streeft naar een ,getrouw beeld" alert te maken. Poogt men soms iets te verbergen? Op deze vraag wil ik gaarne in een volgend artikel nader ingaan.

De samenstelling van het resultaat volgens de veelal gebruikelijke categorische resultatenrekening laat veel te wensen over, wanneer men het gevoerde beleid in de afgelopen periode aan de hand van de jaarrekening wil beoordelen. De organische resultatenrekening is meermalen aanbevolen, maar kennelijk niet overtuigend. Slechts een enkele maatschappij hanteert deze vorm voor de presentatie van haar cijfers.

Op de vergadering van 26 en 27 september 1973, waarin de GBR definitief werden vastgesteld, werd het artikel 17 van het ontwerp gewijzigd, in die zin dat er gesproken kan worden van een versoepeling. Immers, toegevoegd werd de frase ,als in de gegeven omstandigheden vereist is". Kennelijk acht men 
dit voldoende om die situatie te omzeilen, die in de toelichting van het ontwerp omschreven is, n.l. een afkeurende verklaring gecombineerd met de troostrijke mededeling, dat de verantwoording voldoet aan de door de Wet op het L.v.b. gestelde eisen.

$\mathrm{Nu}$ de hernieuwde opstelling der beroepsregelen niet geleid heeft tot een duidelijke positiekeuze in dezen, resteert slech ts de hoop op verbetering. Het Amerikaanse systeem, waarbij de beroepsorganisatie de regels vaststelt (zodat de accountants zich als het ware collectief opstellen) boekte op dit punt duidelijk resultaat ten behoeve van een betere verslaglegging.

\section{Samenvatting}

In dit artikel wordt getracht, uitgaande van een geconstateerde realiteit, aansluiting te zoeken met gevoerde discussies en beroepsreglementering.

Opmerkelijk wordt het geacht, dat de controle-ervaring, opgedaan bij l.v.mijen, er niet toe heeft geleid, dat in de discussie met betrekking tot de verhouding ,eigen actie"/,,gebruik interne controle" een overtuigende bijdrage geleverd werd over de deugdelijke grondslag van een controleconceptie, die grotendeels gebaseerd is op de beoordeling van interne controle.

Bij analyse blijkt het deskundigheidsmanco van de controlerend accountant met betrekking tot de Premiereserve erg mee te vallen. Het gebrek aan bedrijfseconomische kennis bij de actuaris daarentegen dient diens verklaring eerder verdacht dan vertrouwenwekkend te maken.

De verwijzing valt onder artikel 16 GBR. Ligt hierin een indirecte verwijzing c.q. sluit dit aan bij vergelijkbare situaties met verklaringen van andere vrije beroepsuitoefenaars? Een merkwaardige inkonsekwentie wordt hier geconstateerd. Vervolgens is de logica van het wel verwijzen naar een bepaalde deskundigheid en het (terecht) niet mogen verwijzen naar een andere (de eigen) deskundigheid, wanneer deze in beide gevallen belichaamd is in een intern functionaris, ver te zoeken. Beoordeeld vanuit het standpunt van de onafhankelijkheidseisen die het maatschappelijk verkeer geacht wordt te stellen.

De in art. 36 W.J.O. vastgelegde superioriteit van de Verzekeringskamer ten opzichte van de Ondernemingskamer doet een accountant vreemd aan. Is een ,getrouw beeld" dan in strijd met de vereiste solvabiliteit ten opzichte van polishouders?

Er kan m.i. weinig twijfel bestaan over de informatieve waarde van de categorische Verlies- en Winstrekening.

Bij de definitieve vaststelling der beroepsregels is er kennelijk niet naar gestreefd op dit punt iets te forceren, hoewel er in het ontwerp duidelijke tendensen in die richting waren te onderkennen. In het licht van ontwikkelingen in het buitenland, o.a. in de U.S.A. en Canada, kan men dit betreuren.

Tenslotte is de mogelijke waarde van dit artikel niet beperkt tot het ,,specialistische terrein" van de controle bij de l.v.mij, maar betreft ze veeleer alle mijen en fondsen waar pensioenen in ondergebracht zijn. 


\section{Literatuur}

I Algemeen

1 J. W. Muis, Fundamenteel versus helder denken? De accountant/december 1974.

2 R. W. Starreveld, Leer van de Administratieve Organisatie, deel 2, derde druk, 1968.

3 Wet op de Jaarrekening van Ondernemingen. Editie Schuurman en Jordens, 1970.

4 Wet op het Levensverzekeringbedrijf 1922. Editie Schuurman en Jordens, 10e druk, 1974.

II Betekenis interne controle voor certificerend accountant/,eigen actie”. De gebruikelijke reeks publikaties wordt bekend verondersteld. Vervolgens:

1 Prof. Drs. R. Burgert, De betekenis van de budgettering voor de accountantscontrole. De Naamloze Vennootschap, febr./mrt. 1960.

2 Prof. Drs. G. L. Groeneveld, Moderne Technieken van accountantscontrole. MAB februari 1973.

3 H. J. de Heer, Controlemiddelen van de accountant. Handboek Accountancy, sup. 10, sept. 1974.

4 Prof. Drs. L. van Kampen, Klassiek of Modern. MAB januari 1974.

5 Prof. Drs. H. H. J. Nordemann, De betekenis der eigen actie. MAB april 1974.

6 J. P. van Rossem, Criteria voor de keuze der te hanteren methoden en middelen. MAB april 1974.

7 Drs. A. L. Westers, De betekenis van interne organisatie en interne controle. MAB maart 1974. III De accountant, de actuaris en de verklaring.

1 Commissie van Advies inzake Beroepsaangelegenheden. De verhouding van de accountant tot de actuaris bij levensverzekeringsmaatschappijen en de invloed hiervan op de accountantsverklaring. De Accountant, november 1954.

2 Prof. A. B. Frielink, De GBR verklaard. Mei 1974.

3 L. G. v. d. Hoek, De verslaglegging bij levensverzekeringsmaatschappijen, in het bijzonder die van de resultaten. MAB Jan./febr. 1946 (50 jaar MAB, deel 3, mei 1974).

4 Drs. I. Kleerekoper, De accountant in zijn verhouding tot andere beroepen. MAB oktober 1974.

5 Ch. Modijefsky, De accountantscontrole bij verzekeringsbedrijven. Handboek Accountancy, supplement 6, juni 1973.

6 NIVA-bestuur, De verantwoordelijkheid van de accountant met betrekking tot de reserves. Jaarverslag NIVA 1944, punt 11.

7 Ontwerp GBR met Toelichting. Bijlage Staatscourant nr. 145 van 30 juli 1973.

$8 G B R$, Staatscourant nr. 236 van 5 december 1973.

IV Buitenland

1 A.I.C.P.A., Audits of Stock Life Insurance Companies, 1972.

2 Barry L. Blazer, The actuary, the C.P.A. and the Audit Guide. C.P.A. Journal, juni 1974.

3 C.I.C.P.A., Financial reporting for life insurance companies, 1974. 